BMJ Paediatrics Open

\section{Parent, patient and clinician perceptions of outcomes during and following neonatal care: a systematic review of qualitative research}

To cite: Webbe J, Brunton G, Ali S, et al. Parent, patient and clinician perceptions of outcomes during and following neonatal care: a systematic review of qualitative research. BMJ Paediatrics Open 2018;2:e000343. doi:10.1136/ bmjpo-2018-000343

- Additional material is published online only. To view please visit the journal online (http://dx.doi.org/10.1136/ bmjpo-2018-000343).

Received 12 July 2018 Revised 9 August 2018 Accepted 14 August 2018
Check for updates

(C) Author(s) (or their employer(s)) 2018. Re-use permitted under CC BY. Published by BMJ.

${ }^{1}$ Neonatal Medicine, Imperial College London, London, UK ${ }^{2}$ UCL Institute of Education, London, UK

${ }^{3}$ Imperial College London, London, UK

Correspondence to Dr Chris Gale; christopher.gale@ imperial.ac.uk

\section{ABSTRACT}

Objective Multiple outcomes can be measured in infants that receive neonatal care. It is unknown whether outcomes of importance to parents and patients differ from those of health professionals. Our objective was to systematically map neonatal care outcomes discussed in qualitative research by patients, parents and healthcare professionals and test whether the frequency with which outcomes are discussed differs between groups.

Design Systematic review of qualitative literature. The following databases were searched: Medline, CINAHL, EMBASE, PsycINF0 and ASSIA from 1997 to 2017. Publications describing qualitative data relating to neonatal care outcomes, reported by former patients, parents or healthcare professionals, were included. Narrative text was analysed and outcomes grouped thematically by organ system. Permutation testing was applied to assess an association between the outcomes identified and stakeholder group.

Results Sixty-two papers containing the views of over 4100 stakeholders were identified; 146 discrete outcomes were discussed; 58 outcomes related to organ systems and 88 to other more global domains. Permutation testing provides evidence that parents, former patients and health professionals reported outcomes with different frequencies $(p=0.037)$.

Conclusions Parents, patients and health professionals focus on different outcomes when discussing their experience of neonatal care. A wide range of neonatal care outcomes are reported in qualitative research; many are global outcomes relating to the overall status of the infant. The views of former patients and parents should be taken into consideration when designing research; the development of a core outcomes set for neonatal research will facilitate this.

\section{INTRODUCTION}

In high-resource settings approximately 1 in 10 babies will require care in a neonatal unit. ${ }^{1}$ Conditions such as preterm birth affect patients' long-term outcomes: consequences include cardiovascular disease in adulthood, ${ }^{2}$ neurosensory impairment, ${ }^{3}$ respiratory disease $^{4}$ and lower rates of employment and

\section{What is already known on this topic?}

Multiple outcomes can be measured in infants that receive neonatal care.

- It is not known which outcomes are considered important by former neonatal patients, parents and healthcare professionals, or whether these differ between groups.

\section{What this study hopes to add?}

- The predominant outcomes identified by parents, former patients and health professionals related to holistic concepts (such as 'normality').

- Significant differences were identified in outcomes discussed by parents, patients and health professionals.

- Differences in neonatal outcomes prioritised by parents, patients and health professionals should be recognised when planning research.

marriage. ${ }^{5}$ Infants born more prematurely tend to have worse outcomes. ${ }^{6}$ As neonatal survival for babies of all gestational ages improves long-term outcomes become more important.

An outcome is the measured effect that illness or treatment has on an individual. ${ }^{7}$ Parents and patients are rarely involved in outcome selection in paediatric research. ${ }^{8}$ Poor outcome selection causes research waste $^{9}$ : research produced is not relevant to patients' lives. Neonatal care, and the underpinning research, should focus on outcomes important to those it affects most: former neonatal patients, parents and healthcare professionals. ${ }^{910}$ Identifying these outcomes is crucial to ensure research is relevant and efficient. $^{9}{ }^{11}$ Qualitative research provides a rich description of complex phenomena such as neonatal care. ${ }^{12}$ One commonly used approach to identify outcomes of importance 
to stakeholders is primary qualitative research. Considerable qualitative research exploring how parents and health professionals perceive neonatal care has been conducted previously ${ }^{13}{ }^{14}$; therefore, by systematically reviewing published qualitative research it is possible to map the outcomes discussed by different groups. This review does not include all research on how stakeholders perceive neonatal care: it is focused on how former patients, parents and health professionals perceive the outcomes of this care.

In this study we aimed to map the range of outcomes identified in qualitative literature by different stakeholder groups: parents, ex-neonatal patients and healthcare professionals. We also wanted to test the hypotheses that stakeholder groups prioritise outcomes differently, and that outcomes identified differ by infant gestational age category.

This work is a component of a wider programme to compile a core outcomes set for neonatology. ${ }^{15} \mathrm{~A}$ core outcomes set is an agreed collection of important outcomes identified through robust consensus methods by all key stakeholder groups. ${ }^{7}$ The results of this study will be combined with the results of a systematic review of outcomes reported in clinical trials. ${ }^{16}$ These will be used as the starting point for the consensus process to determine a core outcomes set. ${ }^{15}$

\section{METHODS}

We registered this systematic review prospectively on PROSPERO (prospective register of systematic reviews): CRD42016037874. ${ }^{17}$ We conducted the review according to Preferred Reporting Items for Systematic Reviews and Meta-Analyses (PRISMA) guidelines. ${ }^{18}$ We searched the following databases: Medical Literature Analysis and Retrieval System Online (MEDLINE), Cumulative Index to Nursing and Allied Health Literature (CINAHL), Excerpta Medica Database (EMBASE), Psychological Information Database (PsycINFO) and Applied Social Sciences Index and Abstracts (ASSIA). Qualitative or mixed methods studies were included if they contained outcomes identified by stakeholders in the context of babies admitted to a neonatal unit. Full inclusion and exclusion criteria are listed in online supplementary eTable 1 . We considered all studies published from 1 January 1997 to 1 January 2017 in a peer review journal in all languages (where necessary a translation was obtained). The databases were last searched on 14 February 2017. The search strategy used for MEDLINE is described in online supplementary eFigure 1 . The terms derived from this search strategy were translated to other databases.

All identified papers were screened by title and abstract and then by full text. After double-screening a sample of papers and agreeing criteria all screening was completed by one researcher (JW). For quality assurance, a second researcher screened a random $10 \%$ sample of abstracts

\section{Box 1 An example of an outcome hierarchy}

Text extracts to identify or infer a result of clinical care, the 'outcome' such as 'Bonding with parents'.

- Similar 'outcomes' were grouped into thematically linked 'domains' such as 'Relationships with others'.

- 'Outcome domains' relating to similar concepts were grouped into 'categories' such as 'Social.

- We did not address the ways in which an outcome was measured. For example, the 'outcome' 'Parental bonding' could be measured using parent-reported scores or an external assessment.

and titles (CG). Agreement between reviewers was assessed by Cohen's kappa coefficient. ${ }^{19}$

After screening all papers were coded independently by two researchers (JW and CG or GB) using Eppi-Reviewer V.4 software. ${ }^{20}$ Any disagreement was resolved by a third researcher (CG or GB). Data on study design, stakeholder demographics, infant birth characteristics and verbatim text relating to neonatal care outcomes were extracted and stored. Quality assessment of individual studies was not undertaken as it is a controversial area of uncertain value in relation to qualitative research. ${ }^{21}$

All outcomes were grouped according to a previously defined framework of organ systems ${ }^{22}$ using the following domains: cardiovascular, respiratory, gastrointestinal, neurological, genitourinary, infection, skin and development. All three reviewers jointly refined this framework using methods incorporating thematic analysis. ${ }^{23-25}$ Where narrative data did not fit clearly into the domains, dialogue between all reviewers was used to develop new domains. Outcome domains were thematically analysed to develop higher order categories. A new hierarchy was developed to group outcomes because established hierarchies either did not relate well to neonatal care ${ }^{26-28}$ or missed key concepts. ${ }^{7}$ This outcome hierarchy is described in box 1 .

We analysed whether outcomes identified differed by stakeholder groups and by infant gestational age category (using WHO definitions of prematurity) ${ }^{29}$ We used permutation testing ${ }^{30}$ to test for an association between the frequency that outcomes in different domains were identified and the stakeholder group involved. We performed 5000 replications to generate the distribution of the test statistic under the null hypothesis of no association, and compared our results with this distribution. We performed a similar analysis to test for an association between infant gestational age and frequency of outcome reporting. If a significant association was found we explored this further in a post hoc analysis to identify where the observed results differed most from the frequencies expected under the hypothesis of no association established by the permutation analysis.

\section{RESULTS}

Database searches produced 1130 results which were screened and assessed for eligibility (figure 1). After 
applying inclusion and exclusion criteria 62 studies containing the views of 4100 stakeholders were analysed. Agreement between reviewers was high (Cohen's kappa coefficient $=0.81)^{19}$

The 62 included studies reported data from 15 countries; 9 related to full-term infants, 31 to preterm infants (born $<37$ weeks' gestational age) and 20 to extremely preterm infants (born <28 weeks' gestational age). A range of methodologies was used including direct observation (13 studies) and individual (25 studies) or group interviews (13 studies). Questionnaires were used in 21 studies, two of which were Delphi processes. Included studies are described in online supplementary eTable 2.

Included studies involved over 4100 participants. Parents were the most frequently involved stakeholder group (1969 parents in 40 studies; 65\%); former neonatal patients were less commonly included (368 patients in 5 studies; 8\%). Nurses and midwives were the professional group involved most often (1096 involved in 24 studies; 39\%). Three hundred and sixteen doctors were involved in 18 studies (29\%). We also identified 351 additional participants consisting of other family members, teachers, social workers and allied health professionals. In many studies, particularly those employing observation of clinical practice, the total number of research participants was not recorded.

One hundred and forty-six distinct outcomes were extracted from the included studies. Fifty-eight outcomes related to organ systems within the original framework; we were unable to categorise 88 outcomes within the original framework. The final framework is shown in table 1. An example of the thematic analysis leading to the expanded framework is shown in box 2 .

The full inventory of outcomes is listed in online supplementary eTable 3. A table of all outcomes in each study (with verbatim text extracts) is shown in online supplementary eTable 4.

Outcomes were identified relating to all of the organ systems included in the original framework and assigned to an organ system outcome domain category (table 2). The organ system outcome domains most frequently discussed at the study level were 'development' (32 studies; 52\%) and 'gastrointestinal' (24 studies, 39\%). The individual organ system outcomes most frequently discussed were 'language disorders' (8 studies, 13\%), 'visual impairment' (7 studies, 11\%) and 'breast feeding' (7 studies, $11 \%$ ).

The majority of outcomes identified did not relate to individual organ systems. Some related to the overall status of the infant and were assigned to a holistic outcome domain category (table 3). Other domains related to the effects experiencing neonatal care has on parents; these were assigned to a 'Parent focused' outcome domain category (table 4). Another group of domains related to the neonatal care delivered; these were assigned to a 'Healthcare delivery' outcome domain category (table 5). A group of domains was identified relating to the cost of neonatal care; these were assigned to an 'Economic' outcome category (table 6). Finally, a group of outcome domains was identified relating to the relationships neonatal patients develop with others;

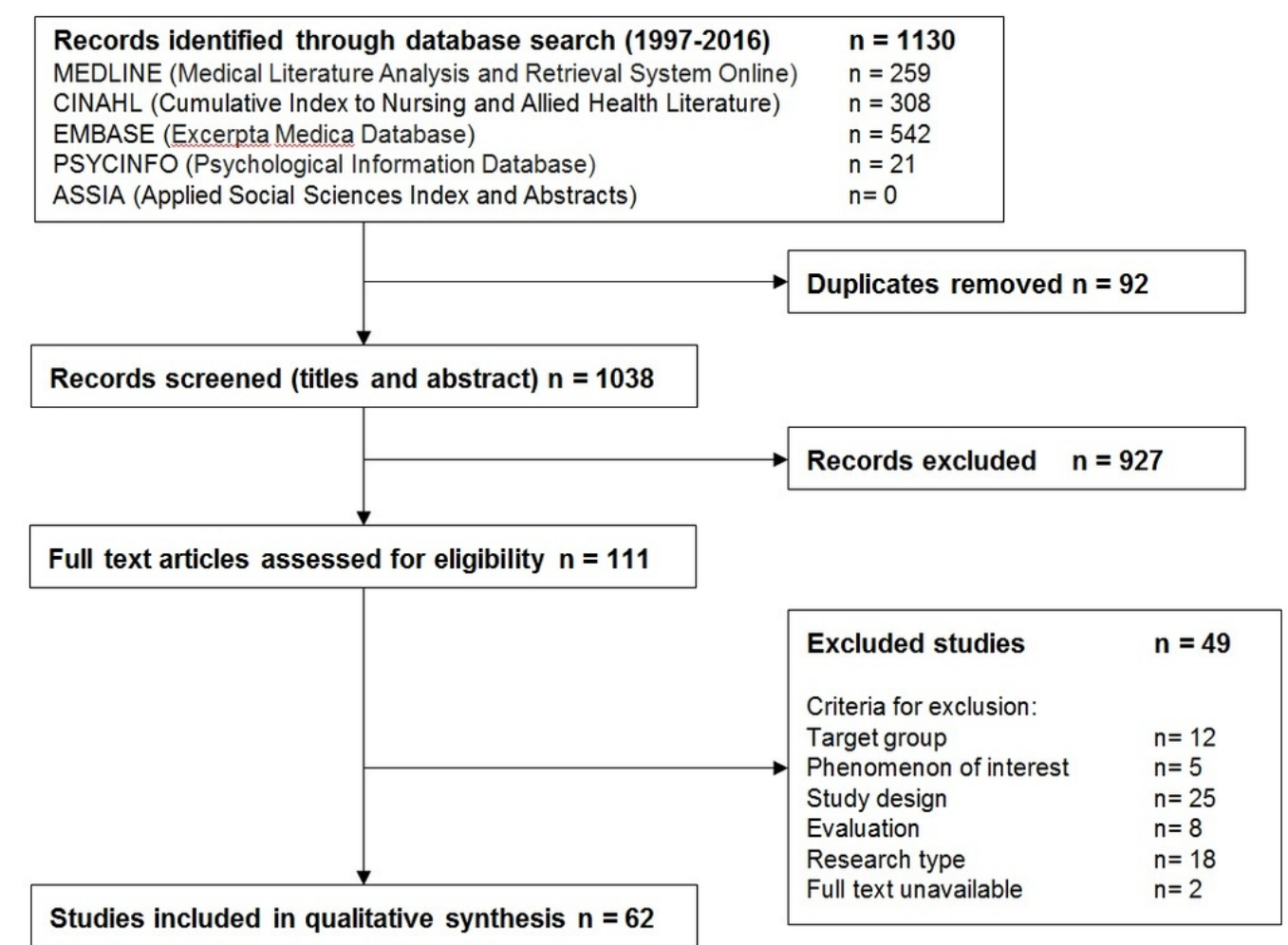

Figure 1 PRISMA flowchart of study selection. 


\begin{tabular}{|c|c|}
\hline $\begin{array}{l}\text { Outcome domain } \\
\text { categories }\end{array}$ & Outcome domains \\
\hline Organ system outcomes & $\begin{array}{l}\text { Cardiovascular } \\
\text { Respiratory } \\
\text { Gastrointestinal } \\
\text { Neurological } \\
\text { Genitourinary } \\
\text { Infection } \\
\text { Skin } \\
\text { Developmental }\end{array}$ \\
\hline Holistic outcomes & $\begin{array}{l}\text { Survival } \\
\text { Growth } \\
\text { Pain } \\
\text { Suffering } \\
\text { Normality } \\
\text { Other outcomes }\end{array}$ \\
\hline Parent-focused outcomes & $\begin{array}{l}\text { Parental support } \\
\text { Other outcomes }\end{array}$ \\
\hline $\begin{array}{l}\text { Healthcare delivery } \\
\text { outcomes }\end{array}$ & $\begin{array}{l}\text { Healthcare workers - knowledge } \\
\text { and competence } \\
\text { Healthcare workers - } \\
\text { Communication } \\
\text { Other outcomes }\end{array}$ \\
\hline Economic outcomes & $\begin{array}{l}\text { Healthcare utilisation } \\
\text { Other outcomes }\end{array}$ \\
\hline Social outcomes & $\begin{array}{l}\text { Psychiatric outcomes } \\
\text { Relationships with others } \\
\text { Other outcomes }\end{array}$ \\
\hline
\end{tabular}

Outcome domain categories and outcome domains added to the original framework marked in italics.

these were assigned to a 'Social' outcome domain category (table 7).

From these outcome domains the most frequently discussed at study level were 'parental support' (30 studies, $48 \%$ ) and 'healthcare workers-communication' (30 studies, $48 \%$ ). The individual outcomes most frequently discussed were 'normality' (16 studies, 26\%) and 'survival' (11 studies, 18\%).

Permutation test analysis showed a statistically significant association $(\mathrm{p}=0.037)$ between different stakeholder groups and outcome categories identified (online supplementary eFigure 3). The frequency with which patients discussed the outcomes was most divergent from the other groups. In particular, patients discussed outcomes relating to the genitourinary, surgical, developmental and pain outcome domains more than would be expected by chance.

We found no statistically significant association $(\mathrm{p}=0.114)$ between gestational age and outcome categories (online supplementary eFigure 2).
Box 2 Example of framework synthesis related to the outcome of 'Normality'. Thematic analysis of verbatim extracts identified a recurring theme

- 'The mother also worried that... Lisa would not have a normal life. ${ }^{A 1}$

- 'Being reassured that he was on line for how old he was...Just reassurance he was doing well. ${ }^{\star 2}$

- 'Finally, a mother called it a developmental land-mark when an older sister dared show her irritation towards her little brother, 'no longer treating him as if he were made of glass. ${ }^{A 3}$

- From this and similar text the outcome of 'Normality' was derived by thematic analysis. It did not fit within the existing outcome hierarchy but was reported extensively, so a new domain was added to the framework again called 'Normality'. This outcome domain relating to the overall status of the infant was similar to outcome domains like 'survival', 'vitality' and 'growth', so these domains were grouped together as an outcome domain category called: 'Holistic outcomes'.

\section{DISCUSSION}

We have systematically reviewed and synthesised the outcomes reported in qualitative research by those with lived experience of neonatal care: patients, parents and healthcare professionals. We show that the patterns of outcomes discussed by former neonatal patients, parents and healthcare professionals are different. This is in keeping with previous single-centre research ${ }^{31}$ and case reports. ${ }^{32}$ This indicates that healthcare professionals should consider whether the outcomes they discuss align with patients and parents' concerns. ${ }^{33}$ Acceptance of the differences shown should form part of the process of shared decision-making in clinical practice. ${ }^{34}$ Poor outcome selection is also a known problem in paediatric research, ${ }^{85}$ involving patients and parents will help reduce research waste. ${ }^{36} 37$

The outcomes identified extend beyond the organ system-specific outcomes commonly reported in clinical trials and include global concepts such as 'normality' of the child in later life, the impact on an infant's family and the healthcare team, financial and time costs and how patients interact with wider society. Our findings are in keeping with observational studies illustrating the widereaching consequences of neonatal illness. ${ }^{38-40}$ Another feature of the outcomes identified is that rather than relating to a specific diagnosis or disease many reflect the global status of the child. Diagnoses like necrotising enterocolitis or retinopathy of prematurity were mentioned less frequently than their consequences, such as feeding difficulties or visual impairment. In general, the outcomes identified indicate that pathological processes and diagnoses are less relevant to patients and parents than the effects they have on day-to-day life. Priority should be given to identifying efficient ways of measuring more global outcomes of neonatal conditions throughout childhood and later life, for example, through robust linkage of neonatal data with education databases. 


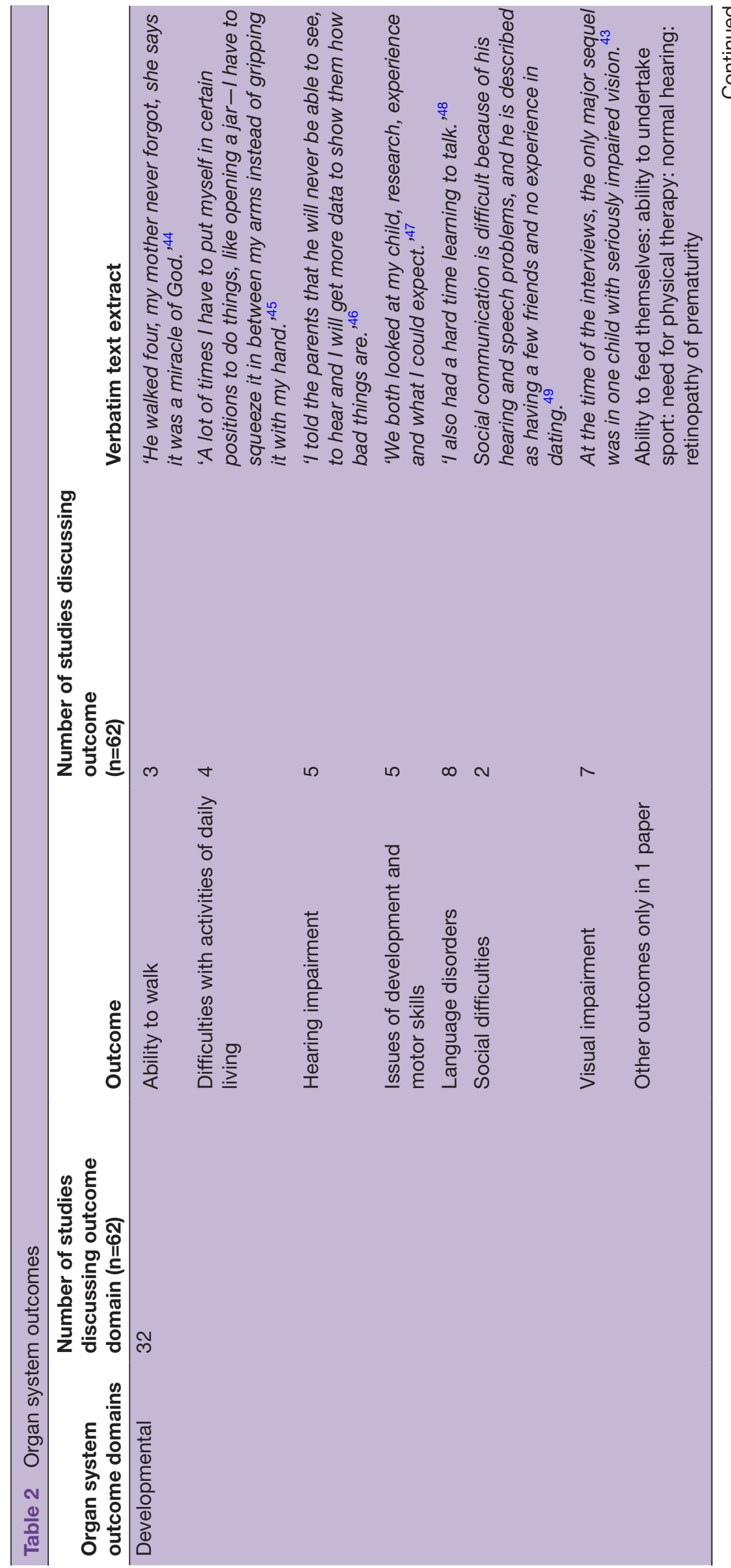




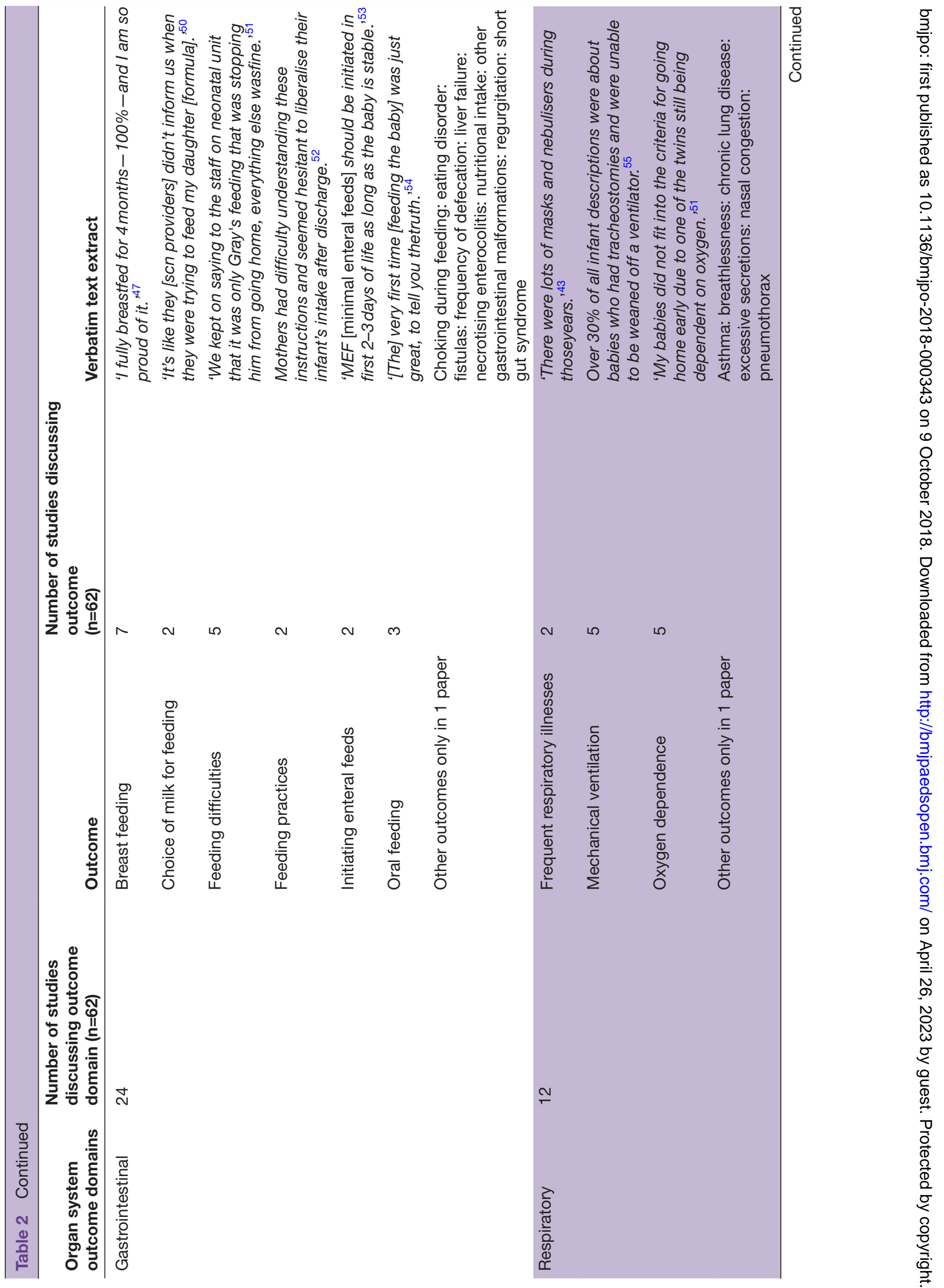




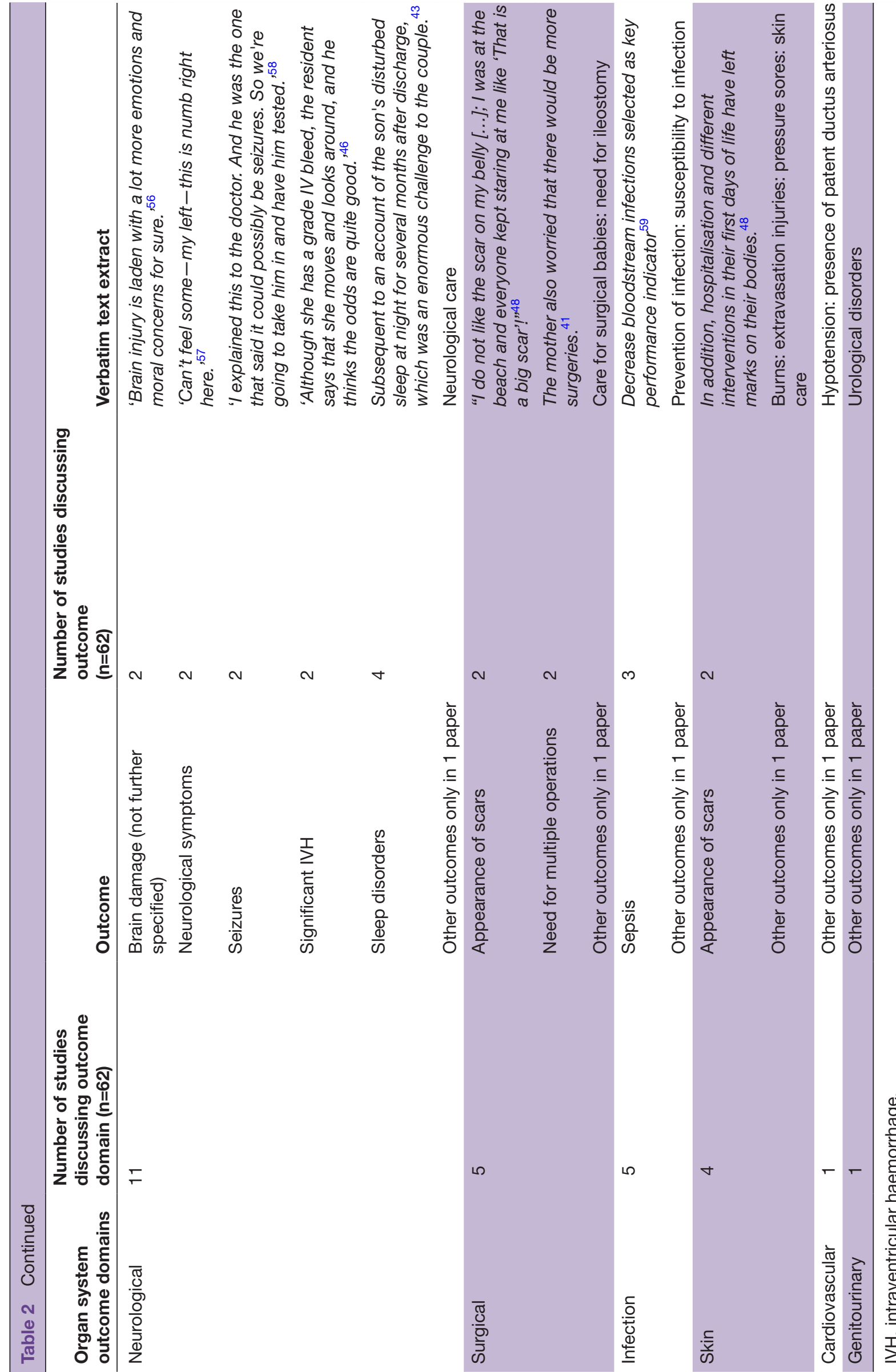




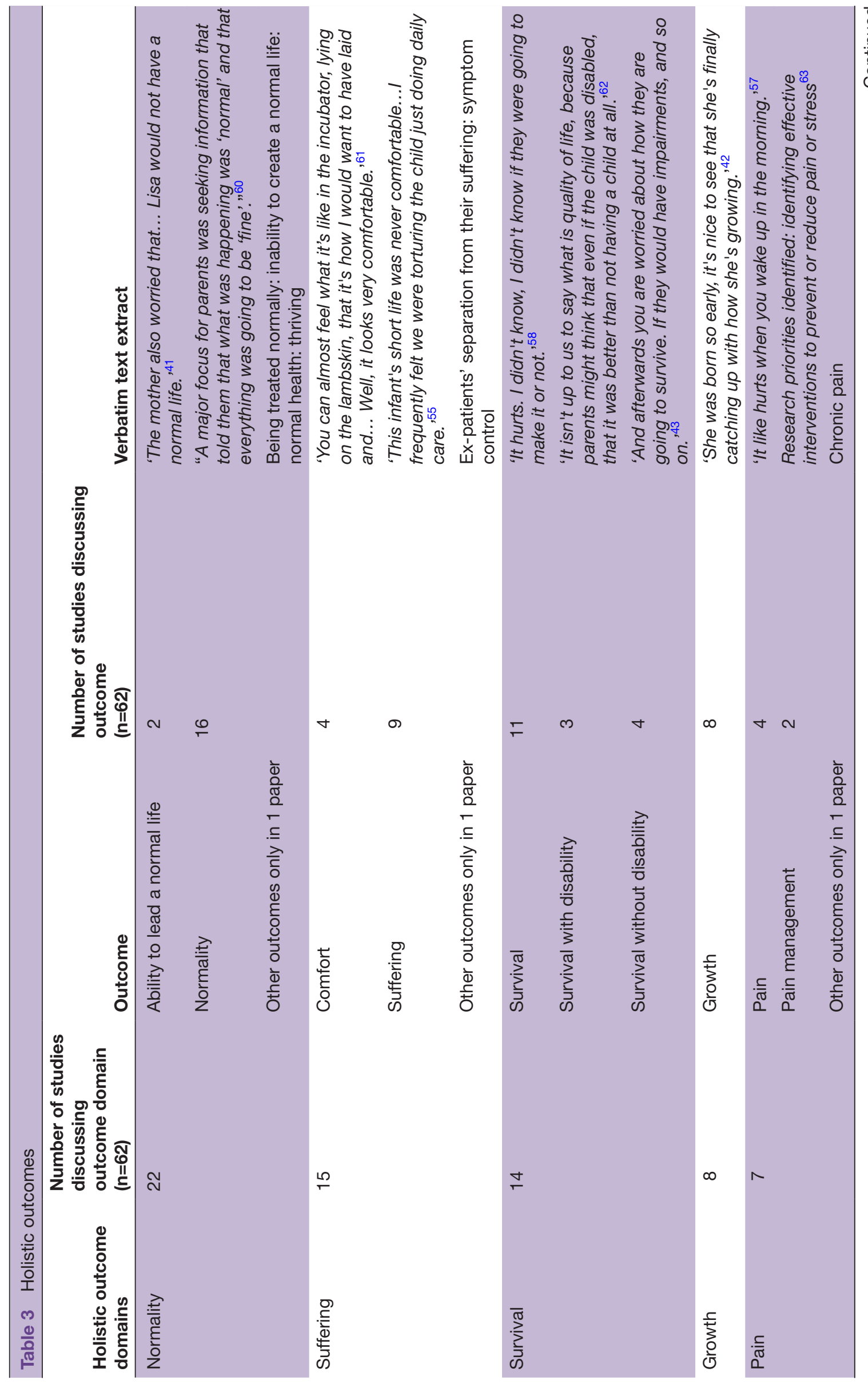




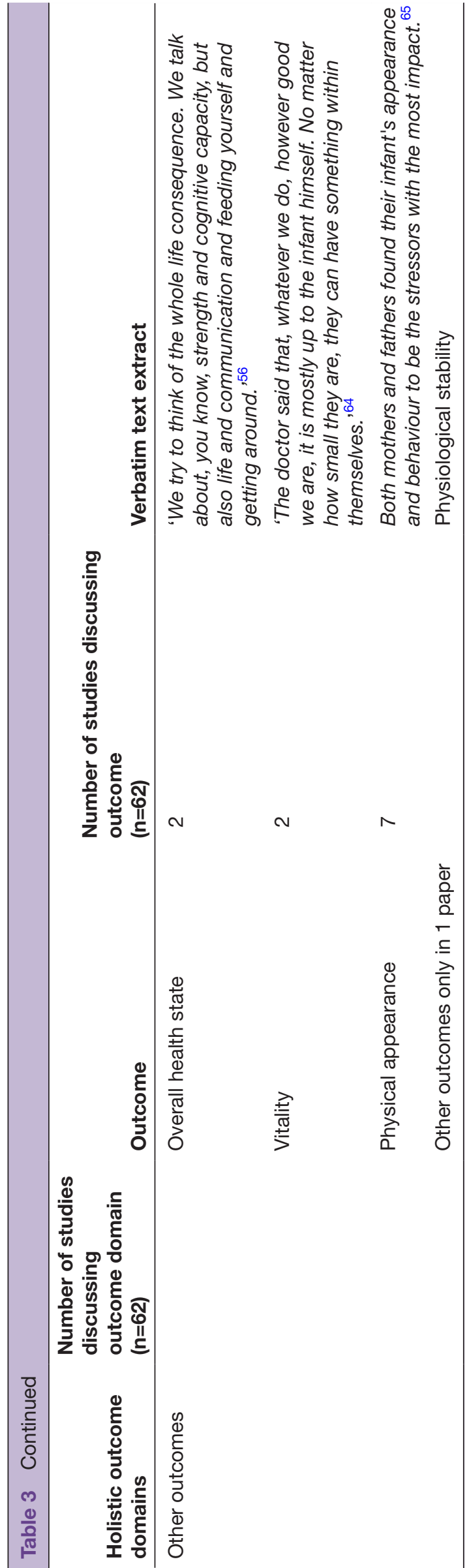

This more holistic approach should extend to how babies are categorised. Our work included an undoubtedly heterogeneous population, but this was driven by discussions with former neonatal patients and parents at the planning stages of this project. They strongly stated that 'a sick baby is a sick baby' regardless of birth weight or gestational age: a statement that is supported by our finding that there was no significant difference in how frequently outcomes were discussed in relation to babies of differing gestational ages. Splitting research populations by arbitrary landmarks not recognised by parents or former patients ${ }^{32}$ may be a source of research heterogeneity.

The strengths of our study included identification and synthesis of outcomes from an international and methodologically diverse range of studies, relating to babies of all gestational ages, and a wide range of stakeholders. We included outcomes that stakeholders spontaneously identified. As a result, we were able to include data from a wider range and diversity of stakeholders than a primary research study could. We followed a preregistered protocol with reporting in line with PRISMA guidelines. ${ }^{18}$ It has been argued that quality assessment is needed in 'mapping' reviews to aid in interpretation and uptake of findings, ${ }^{24}$ but the value of this approach is uncertain. ${ }^{21}$ The consultation phase of our core outcomes set development work will provide the opportunity to critically reflect on the contribution of these findings to our understanding of what constitutes an 'important' outcome in neonatal research.

A limitation of our study is that, in line with many systematic reviews, we are synthesising data from studies that did not explicitly address the research question we are asking. This meant that we combined data about which outcomes parents, patients or healthcare professionals mentioned during research. As a result, we described how frequently outcomes were discussed, rather than the importance assigned by groups to each outcome. Many outcomes were only discussed in a single study. We present them here to show the range and breadth of outcomes discussed, but cannot comment on whether they are more or less important than more frequently mentioned outcomes. Another limitation is that the researchers who undertook the primary qualitative research in the included studies will have influenced our review through their analysis; we reviewed data that was a step removed from the opinions of the stakeholders themselves. However, by following rigorous methodology and employing a comprehensive search strategy we have combined all available data to produce this mapping review.

Trying to measure all of the varied outcomes identified in this work in research would be impractical, if not impossible. This work supports the importance of identifying a core outcomes set, and highlights the importance of input from all stakeholder groups. In other fields, core outcomes sets have successfully aligned patient and healthcare professional research priorities. ${ }^{36}$ 


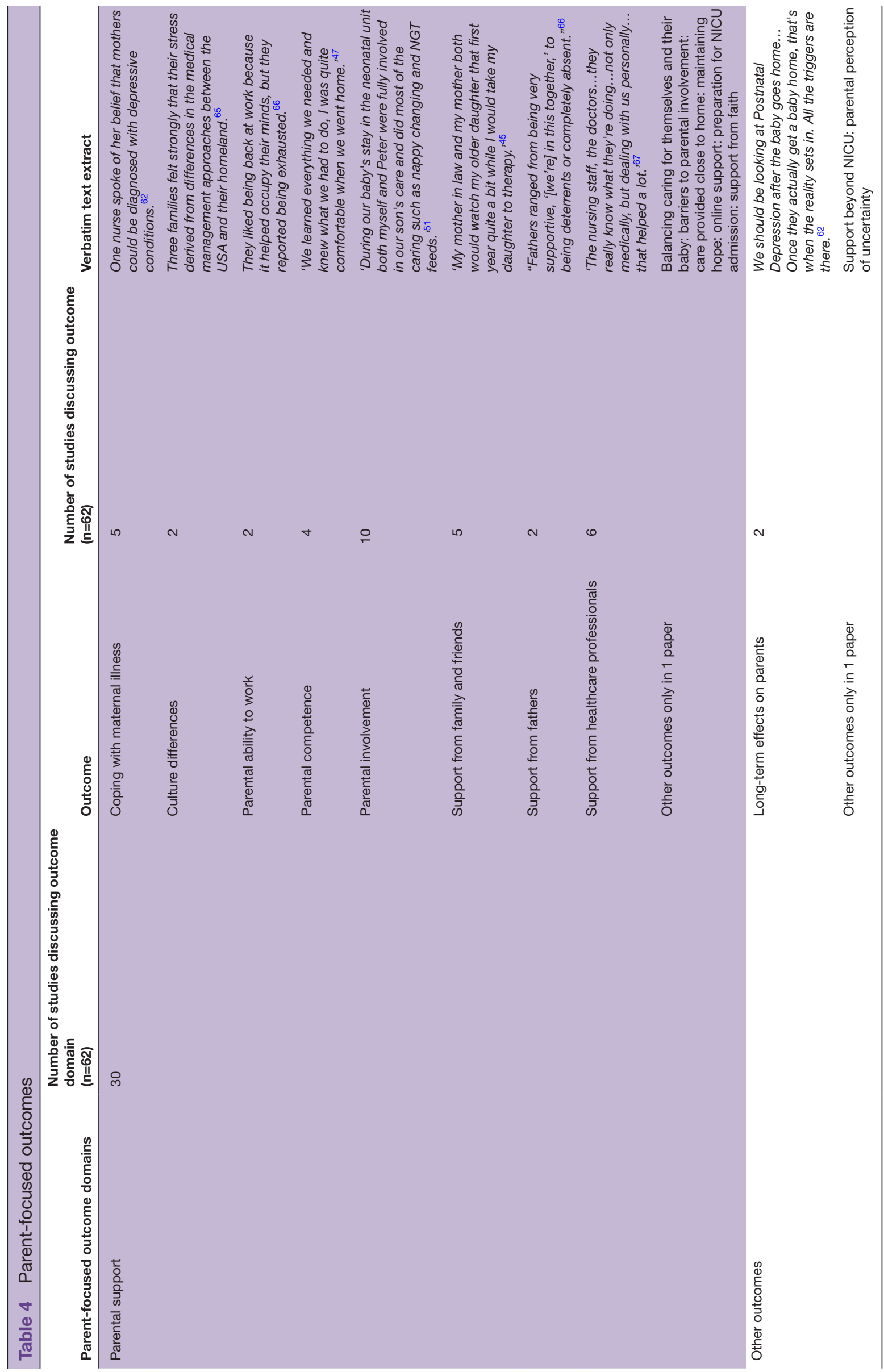




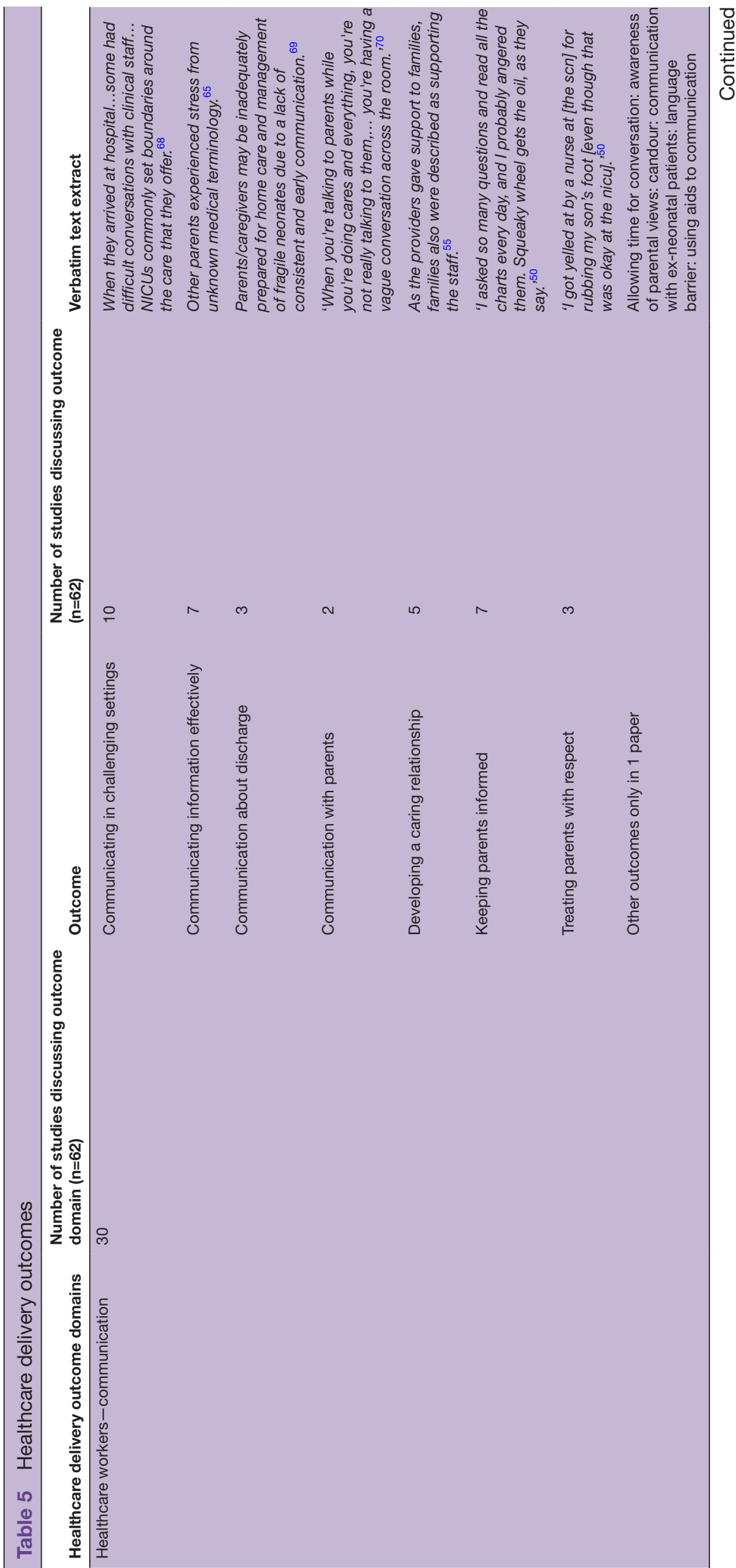

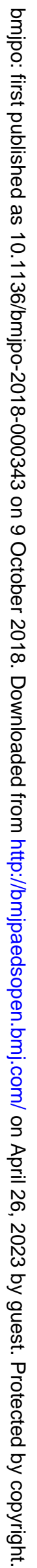




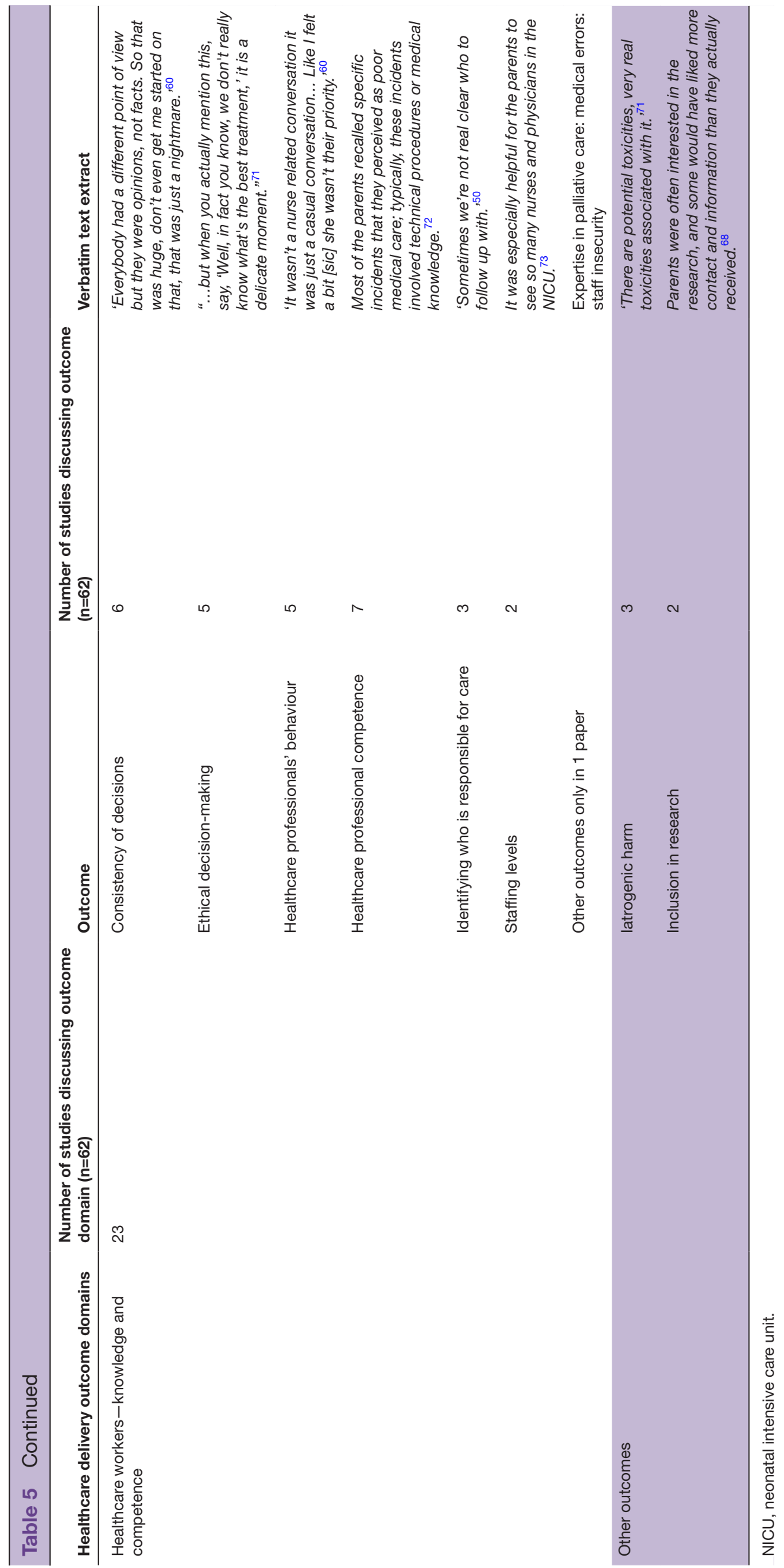


Table 6 Economic outcomes

\begin{tabular}{|c|c|c|c|c|}
\hline $\begin{array}{l}\text { Economic outcome } \\
\text { domains }\end{array}$ & $\begin{array}{l}\text { Number of studies } \\
\text { discussing } \\
\text { outcome } \\
\text { domain }(n=62)\end{array}$ & Outcome & $\begin{array}{l}\text { Number of studies } \\
\text { discussing } \\
\text { outcome } \\
(\mathrm{n}=62)\end{array}$ & Verbatim text extract \\
\hline \multirow[t]{6}{*}{ Healthcare utilisation } & \multirow[t]{6}{*}{15} & Frequent appointments & 2 & $\begin{array}{l}\text { 'I felt left out, I was always missing school because I had to go to the } \\
\text { hospital for check-ups.' }\end{array}$ \\
\hline & & Frequent readmissions & 4 & $\begin{array}{l}\text { The prolonged hospitalisations experienced by children with BPD } \\
\text { and the frequent interactions of families with medical personnel may } \\
\text { result in increased access and opportunities for services for parents } \\
\text { of children with BPD. }{ }^{74}\end{array}$ \\
\hline & & $\begin{array}{l}\text { Inappropriate } \\
\text { treatments }\end{array}$ & 2 & $\begin{array}{l}\text { Community providers... may lack the required knowledge and skills } \\
\text { to manage complex infants, leading to suboptimal office-based care } \\
\text { and perceived overutilisation of the emergency system. }\end{array}$ \\
\hline & & $\begin{array}{l}\text { Need for frequent } \\
\text { treatments }\end{array}$ & 3 & 'There were lots of masks and nebulisers during those years. ${ }^{43}$ \\
\hline & & Need for lifelong care & 3 & $\begin{array}{l}\text { 'When the outcome is disastrous they just expect parents to } \\
\text { take home severely handicapped babies and deal with life-long } \\
\text { problems." }\end{array}$ \\
\hline & & Recurrent sickness & 1 & $\begin{array}{l}\text { 'We've only put him with other children for the past month. The } \\
\text { biggest worry right now is when he is going to get sick. } 58\end{array}$ \\
\hline \multirow[t]{2}{*}{ Other outcomes } & & Duration of admission & 2 & Decrease length of stay selected as key performance indicator ${ }^{59}$ \\
\hline & & Healthcare resources & 3 & $\begin{array}{l}\text { Although respondents frequently discussed the emotional toll to all } \\
\text { concerned, the monetary cost of long-term stays was very rarely } \\
(<1 \%) \text { mentioned. }{ }^{55}\end{array}$ \\
\hline
\end{tabular}

BPD, borderline personality disorder.

Table 7 Social outcomes

\begin{tabular}{|c|c|c|c|c|}
\hline $\begin{array}{l}\text { Social outcome } \\
\text { domains }\end{array}$ & $\begin{array}{l}\text { Number of studies } \\
\text { discussing outcome } \\
\text { domain }(n=62)\end{array}$ & Outcome & $\begin{array}{l}\text { Number of studies } \\
\text { discussing } \\
\text { outcome } \\
(\mathrm{n}=62)\end{array}$ & Verbatim text extract \\
\hline \multirow[t]{6}{*}{$\begin{array}{l}\text { Relationships with } \\
\text { others }\end{array}$} & \multirow[t]{6}{*}{19} & $\begin{array}{l}\text { Bonding with family and } \\
\text { friends }\end{array}$ & 3 & $\begin{array}{l}\text { 'The only thing we might have done...some of our closest } \\
\text { friends...it would have been nice to have them there as well. }{ }^{67}\end{array}$ \\
\hline & & Bonding with parents & 8 & $\begin{array}{l}\text { "I find it a great joy when the mums do hold the baby against } \\
\text { their chest."76 }\end{array}$ \\
\hline & & Effects on family and friends & 7 & $\begin{array}{l}\text { Almost all parents acknowledged the emotional adjustment of } \\
\text { other family members in response to raising a child with physical } \\
\text { impairment. }{ }^{45}\end{array}$ \\
\hline & & Family resources & 2 & $\begin{array}{l}\text { Three families felt overwhelmed by a lack of resources } \\
\text { (especially in the area of family support). }{ }^{65}\end{array}$ \\
\hline & & Peer acceptance & 2 & $\begin{array}{l}\text { I've had } 4 \text { year-olds tell me the other kids don't want to play with } \\
\text { them cause they have a dumb arm. }{ }^{57}\end{array}$ \\
\hline & & \multicolumn{2}{|l|}{ Other outcomes only in 1 paper } & $\begin{array}{l}\text { Childhood happiness: overprotective parent-child relationship: } \\
\text { psychological coping }\end{array}$ \\
\hline \multirow[t]{3}{*}{ Psychiatric } & \multirow[t]{3}{*}{7} & Need for educational support & 7 & $\begin{array}{l}\text { The patient is at an age-appropriate grade level but attends } \\
\text { resource classes in math and achieves only average grades in } \\
\text { other areas. }{ }^{49}\end{array}$ \\
\hline & & Psychiatric disorder & 3 & $\begin{array}{l}\text { The mother is very focused on the boys' physical and emotional } \\
\text { symptoms. }{ }^{9}\end{array}$ \\
\hline & & Other outcomes only in 1 paper & & Autism: behavioural disturbances: dyslexia: mood disorders \\
\hline Other outcomes & & Other outcomes only in 1 paper & & Schooling: self-identifying as premature \\
\hline
\end{tabular}

\section{CONCLUSION}

Parents, patients and clinicians report a wide range of neonatal care outcomes. Parents and patients focus on different outcomes than health professionals. Outcomes reported do not map to organ systems commonly addressed in clinical trials, many are global outcomes. We suggest that the views of former patients and parents should be taken into consideration by researchers and funding bodies.
Acknowledgements The authors are grateful to Louise Wann (West Middlesex University Hospital) for her contributions running the database searches.

Collaborators COIN Project Steering Group: Elsa Afonso; lyad Al-Muzaffar; Ginny Brunton; James Duffy; Chris Gale; Anne Greenough; Nigel Hall; Marian Knight; Jos Latour; Neil Marlow; Neena Modi; Laura Noakes; Julie Nycyk; Mehali Patel; Angela Richard-Londt; James Webbe; Ben Wills-Eve.

Contributors JW and CG conceived this systematic review. This protocol was created by JW, GB and CG. Searches were performed by LW. All search results were reviewed by JW and assessed by the eligibility criteria. Quality assurance was completed by CG. Coding and result synthesis was completed by JW, GB and 
CG. Statistical analysis was completed by NL. The first draft of the manuscript was written by JW, CG, GB and NL. NM edited and reviewed the manuscript. It was approved by JW, CG, GB, SA, LW, NL, NM and the COIN Steering Group.

Funding This research is sponsored by Imperial College London and supported by an MRC Clinician Scientist Fellowship award to CG (MR/N008405/1) and salary support for JW from the Portland Hospital.

Disclaimer The Imperial College London, the MRC and the Portland Hospital had no involvement in the research or this publication.

Competing interests None declared.

Patient consent Not required.

Provenance and peer review Not commissioned; externally peer reviewed.

Data sharing statement Requests for access to data should be addressed to the corresponding author.

Open access This is an open access article distributed in accordance with the Creative Commons Attribution 4.0 Unported (CC BY 4.0) license, which permits others to copy, redistribute, remix, transform and build upon this work for any purpose, provided the original work is properly cited, a link to the licence is given, and indication of whether changes were made. See: https://creativecommons.org/ licenses/by/4.0/.

\section{REFERENCES}

1. Harrison W, Goodman D. Epidemiologic Trends in Neonatal Intensive Care, 2007-2012. JAMA Pediatr 2015;169:855-62.

2. Gluckman PD, Hanson MA, Cooper C, et al. Effect of in utero and early-life conditions on adult health and disease. N Engl J Med 2008;359:61-73.

3. Doyle LW, Anderson PJ. Adult outcome of extremely preterm infants. Pediatrics 2010;126:342-51.

4. Roberts G, Cheong JL. Long-term growth and general health for the tiniest or most immature infants. Semin Fetal Neonatal Med 2014;19:118-24.

5. Saigal S, Day KL, Van Lieshout RJ, et al. Health, wealth, social integration, and sexuality of extremely low-birth-weight prematurely born adults in the fourth decade of life. JAMA Pediatr 2016;170:678-86

6. Boyle EM, Poulsen G, Field DJ, et al. Effects of gestational age at birth on health outcomes at 3 and 5 years of age: population based cohort study. BMJ 2012;344:e896.

7. Williamson PR, Altman DG, Bagley $\mathrm{H}$, et al. The COMET Handbook: version 1.0. Trials 2017;18.

8. Sinha IP, Williamson PR, Smyth RL. Outcomes in clinical trials of inhaled corticosteroids for children with asthma are narrowly focussed on short term disease activity. PLoS One 2009;4:e6276.

9. Heneghan C, Goldacre B, Mahtani KR. Why clinical trial outcomes fail to translate into benefits for patients. Trials 2017;18:122.

10. Goodare $\mathrm{H}$, Smith $\mathrm{R}$. The rights of patients in research. $B M J$ 1995;310:1277-8

11. Staley K. Exploring Impact: Public involvement in NHS, public health and social care research. Eastleigh: INVOLVE, 2009.

12. Sofaer S. Qualitative methods: what are they and why use them? Health Serv Res 1999;34(5 Pt 2):1101-18.

13. POPPY Steering Group. Family-centred care in neonatal units. $A$ summary of research results and recommendations from the POPPY project. London: NCT, 2009.

14. Kain VJ. An exploration of the grief experiences of neonatal nurses: a focus group study. J Neonatal Nur 2013;19:80-8.

15. Webbe J, Brunton G, Ali S, et al. Developing, implementing and disseminating a core outcome set for neonatal medicine. BMJ Paediatr Open 2017;1.

16. Ali S, Webbe J, Duffy J, Modi N, Gale C, et al. eds. Outcome reporting in trials involving preterm infants: a systematic review. Amsterdam: COMET VI, 2016.

17. PROSPERO database International prospective register of systematic reviews, 2017. A systematic review of qualitative research into parental, patient and clinician perceptions of outcomes in neonatal medicine. http://www.crd.york.ac.uk/prospero/display record.asp?ID=CRD42016037874

18. Moher D. Preferred reporting items for systematic reviews and metaanalyses: the prisma statement. Ann Intern Med 2009;151:264-9.

19. Landis JR, Koch GG. The measurement of observer agreement for categorical data. Biometrics 1977;33:159-74.

20. Thomas J, Brunton J, Graziosi S. EPPI-Reviewer 4: software for research synthesis. EPPI-Centre Software. London: Social Science Research Unit, Institute of Education, University of London, 2010.
21. Collier D, Mahoney J. Insights and pitfalls: selection bias in qualitative research. World Politics 1996;49:56-91.

22. NHS Digital, 2017. National Neonatal Data Set. http://www. datadictionary.nhs.uk/data dictionary/messages/clinical_data sets/ data_sets/national_neonatal_data_set/national_neonatal_data_set_episodic_and_daily_care_fr.asp?shownav $=1$

23. Arksey H, O'Malley L. Scoping studies: towards a methodological framework. Int J Soc Res Methodol 2005;8:19-32.

24. Levac D, Colquhoun H, O'Brien KK. Scoping studies: advancing the methodology. Implement Sci 2010;5:69.

25. Thomas J, Harden A, Newman M. Synthesis: combining results systematically and appropriately. In: Gough D, Oliver S, Thomas J, eds. An introduction to systematic reviews. 2 nd edn. London: Sage, 2017:178-226.

26. Bakas T, McLennon SM, Carpenter JS, et al. Systematic review of health-related quality of life models. Health Qual Life Outcomes 2012;10:134

27. Porter ME. What is value in health care? N Engl $\mathrm{J} \mathrm{Med}$ 2010;363:2477-81

28. Carpenter WR, Meyer AM, Abernethy AP, et al. A framework for understanding cancer comparative effectiveness research data needs. J Clin Epidemiol 2012;65:1150-8.

29. Mo D. Born too soon: the global action report on preterm birth Geneva: World Health Organization, 2012.

30. Ludbrook J. Advantages of permutation (randomization) tests in clinical and experimental pharmacology and physiology. Clin Exp Pharmacol Physiol 1994;21:673-86.

31. Janvier A, Farlow B, Baardsnes J, et al. Measuring and communicating meaningful outcomes in neonatology: A family perspective. Semin Perinatol 2016;40:571-7.

32. Staub K, Baardsnes J, Hébert N, et al. Our child is not just a gestational age. A first-hand account of what parents want and need to know before premature birth. Acta Paediatr 2014;103:1035-8.

33. Pearce R, Baardsnes J. Term MRI for small preterm babies: do parents really want to know and why has nobody asked them? Acta Paediatr 2012;101:1013-5.

34. Charles C, Gafni A, Whelan T. Shared decision-making in the medical encounter: what does it mean? (or it takes at least two to tango). Soc Sci Med 1997;44:681-92.

35. Gardner W, Kelleher KJ. Core quality and outcome measures for pediatric health. JAMA Pediatr 2017;171:827-8.

36. de Wit M, Abma T, Koelewijn-van Loon M, et al. Involving patient research partners has a significant impact on outcomes research: a responsive evaluation of the international OMERACT conferences. BMJ Open 2013;3:e002241.

37. INVOLVE. Public involvement in research: values and principles framework. Eastleigh: INVOLVE, 2015.

38. Saigal S, Doyle LW. An overview of mortality and sequelae of preterm birth from infancy to adulthood. Lancet 2008;371:261-9.

39. Muller-Nix C, Forcada-Guex M, Pierrehumbert B, et al. Prematurity, maternal stress and mother-child interactions. Early Hum Dev 2004;79:145-58.

40. Hall EO. A double concern: grandmothers' experiences when a smal grandchild is critically ill. J Pediatr Nurs 2004;19:61-9.

41. Docherty SL, Lowry C, Miles MS. Poverty as context for the parenting experience of low-income Lumbee Indian mothers with a medically fragile infant. Neonatal Netw 2007;26:361-9.

42. Hussey-Gardner BT, Wachtel RC, Viscardi RM. Parent perceptions of an NICU follow-up clinic. Neonatal Netw 1998;17:33-9.

43. Lou H, Pedersen BD, Hedegaard M. Questions never asked. Positive family outcomes of extremely premature childbirth. Qual Life Res 2009;18:567-73.

44. Arruda DC, Marcon SS. [Family experience of dealing with sequels of the prematurity of a child]. Rev Bras Enferm 2010;63:595-602.

45. Squitieri L, Larson BP, Chang KW, et al. Understanding quality of life and patient expectations among adolescents with neonatal brachial plexus palsy: a qualitative and quantitative pilot study. $J$ Hand Surg Am 2013;38:2387-97.

46. Orfali K. Parental role in medical decision-making: fact or fiction? A comparative study of ethical dilemmas in French and American neonatal intensive care units. Soc Sci Med 2004;58:2009-22.

47. Brødsgaard A, Zimmermann R, Petersen M. A preterm lifeline: Early discharge programme based on family-centred care. J Spec Pediatr Nurs 2015;20:232-43.

48. Leavy P, Violeta Prina M, Martínez Cáceres MJ, et al. Social representations of premature birth from the perspective of individuals born preterm in the 1990s. Arch Argent Pediatr 2015;113:6-11.

49. Votteler TP, Lipsky K. Long-term results of 10 conjoined twin separations. J Pediatr Surg 2005;40:618-29. 
50. Hanrahan K, Gates M, Attar MA, et al. Neonatal back transport: perspectives from parents of Medicaid-insured infants and providers. Neonatal Netw 2007;26:301-11.

51. Cescutti-Butler L. Eliciting parental views regarding early discharge to home care for premature infants. Infant 2009;5:23-8.

52. Reyna BA, Pickler RH, Thompson A. A descriptive study of mothers experiences feeding their preterm infants after discharge. Adv Neonatal Care 2006;6:333-40.

53. Malhotra Y, Nzegwu N, Harrington J, et al. Identifying Barriers to Initiating Minimal Enteral Feedings in Very Low-Birth-Weight Infants: A Mixed Methods Approach. Am J Perinatol 2016;33:47-56.

54. Stevens EE, Gazza E, Pickler R. Parental experience learning to feed their preterm infants. Adv Neonatal Care 2014;14:354-61.

55. Catlin A. Extremely long hospitalizations of newborns in the United States: data, descriptions, dilemmas. Adv Neonatal Care 2008;8:125-32.

56. Rasmussen LA, Bell E, Racine E. A qualitative study of physician perspectives on prognostication in Neonatal Hypoxic Ischemic Encephalopathy. J Child Neurol 2016;31:1312-9.

57. Chang KW, Austin A, Yeaman J, et al. Health-Related quality of life components in children with neonatal brachial plexus palsy: a qualitative study. $P m$ R 2017;9:383-91.

58. Holditch-Davis D, Bartlett TR, Blickman AL, et al. Posttraumatic stress symptoms in mothers of premature infants. J Obstet Gynecol Neonatal Nurs 2003;32:161-71.

59. Rohsiswatmo R, Rafika S, Marsubrin PM. Prevention and control of blood stream infection using the balanced scorecard approach. Acta Med Indones 2014;46:209-16.

60. Jones L, Taylor T, Watson B, et al. Negotiating care in the special care nursery: parents' and nurses' perceptions of nurse-parent communication. J Pediatr Nurs 2015;30:e71-80.

61. Brinchmann BS, Nortvedt P. Ethical decision making in neonatal units--the normative significance of vitality. Med Health Care Philos 2001:4:193-200

62. Green J, Darbyshire P, Adams A, et al. Desperately seeking parenthood: neonatal nurses reflect on parental anguish. J Clin Nurs 2015;24:1885-94.

63. Wielenga JM, Tume LN, Latour JM, et al. European neonatal intensive care nursing research priorities: an e-Delphi study. Arch Dis Child Fetal Neonatal Ed 2015;100:F66-71.
64. Brinchmann BS. 'They have to show that they can make it': vitality as a criterion for the prognosis of premature infants. Nurs Ethics 2000;7:141-7.

65. Lee SY, Lee KA, Rankin SH, et al. Acculturation and stress in Chinese-American parents of infants cared for in the intensive care unit. Adv Neonatal Care 2005;5:315-28.

66. Sisk P, Quandt S, Parson N, et al. Breast milk expression and maintenance in mothers of very low birth weight infants: supports and barriers. J Hum Lact 2010;26:368-75.

67. Armentrout $D$. Living with grief following removal of infant life support: parents' perspectives. Crit Care Nurs Clin North Am 2009;21:253-65.

68. Snowdon C, Brocklehurst P, Tasker R, et al. Death, bereavement and randomised controlled trials (BRACELET): a methodological study of policy and practice in neonatal and paediatric intensive care trials. Health Technol Assess 2014;18:1.

69. Moyer VA, Singh H, Finkel KL, et al. Transitions from neonatal intensive care unit to ambulatory care: description and evaluation of the proactive risk assessment process. Qual Saf Health Care 2010;19:i26-30.

70. Turrill S. A focus of care for neonatal nursing: the relationship between neonatal nursing practice and outcomes. Part 2. Paediatr Nurs 2003;15:30.

71. Garcia J, Elbourne D, Snowdon C. Equipoise: a case study of the views of clinicians involved in two neonatal trials. Clin Trials 2004:1:170-8.

72. Kavanaugh K. Parents' experience surrounding the death of a newborn whose birth is at the margin of viability. J Obstet Gynecol Neonatal Nurs 1997:26:43-51.

73. Griffin T, Kavanaugh K, Soto CF, et al. Parental evaluation of a tour of the neonatal intensive care unit during a high-risk pregnancy. $J$ Obstet Gynecol Neonatal Nurs 1997;26:59-65.

74. Short EJ, Klein NK, Lewis BA, et al. Cognitive and academic consequences of bronchopulmonary dysplasia and very low birth weight: 8-year-old outcomes. Pediatrics 2003;112:e359.

75. Hefferman P, Heilig S. Giving moral distress a voice: ethical concerns among neonatal intensive care unit personnel. Camb Q Healthc Ethics 1999;8:173-8

76. Chia P, Sellick K, Gan S. The attitudes and practices of neonatal nurses in the use of kangaroo care. Aust J Adv Nurs 2006;23:20-7. 